\title{
The Path of China's Integration of Culture and Tourism Under the "New Normal" of China's Economy
}

\author{
Changhua Lin \\ Fujian Academy of Social Sciences \\ Fuzhou, China 350001
}

\begin{abstract}
So-called "strategic pillar industry" of tourism and cultural industries which have great potential for development, are increasingly showing a good integration and development. Cultural industries are the core characteristic for tourism, and the development of tourism is also a significant way to develop and strengthen Cultural industries. Cultural tourism is the generation of Cultural industries combined with Tourism, but there appeared many problems in the development of the national Cultural tourism. This paper analyzes the problems existing in the development of Chinese cultural tourism, and on this basis attempts to put forward the main measures of the future development of China's tourism industry, and put forward the countermeasures and suggestions for the development of cultural tourism to promote the integration of culture and Tourism, and provide the reference for the government.
\end{abstract}

Keywords-culture and tourism; tourism economy; The Belt and Road initiative; new normal

\section{INTRODUCTION}

As everyone knows, tourism is known as "smokeless industry" and "sunrise industry". It has the characteristics of high relevance, wide coverage, strong radiation and great power. It is not only an important part of modern service industry, but also a leading role in promoting the rapid development of modern service industry. At present, China has entered the middle or later stage of industrialization. It is the time to promote the overall balanced and high quality development of regional economy through the rapid development of modern service industry and especially the tourism industry, so as to realize the transition of national economy smoothly in China. It is the inevitable trend that the advantages of the historical culture and tourism resources in the underdeveloped areas are transformed into development advantages In the process of this transformation. Therefore, fully excavating the potential of historical culture and tourism resources, and promoting the deep integration of culture and tourism, promoting the leap development of Chinese cultural tourism industry, stimulating the ultranormal development of modern service industry, making it to be the leading industry which supporting the mode of "development and upgrading, surpassing leapfrog and ecological civilization" in China, so that they will be able to make better use of their advantages as late starters in the related regions, and it will be the inevitable choice to develop and upgrade in this area.

\section{The PRESENT SituAtion OF THE DEVELOPMENT OF CHINESE CUlTURAL TOURISM INDUSTRY}

At present, China's tourism industry is in the critical period of industrial transformation and upgrading, the industry has a good momentum of development with a bright future. Overall, the development of tourism industry in China has entered a new level of development. For many years, the development of China's tourism industry has achieved remarkable results. The transformation and development of the industry has accelerated, and the tourism economy has continued to grow. It has gradually become an important support for the development of the service industry in China. According to China's national statistical bulletin, there were 5 billion domestic tourists in 2017, an increase of $12.8 \%$ over the previous year, and domestic tourism revenue has reached 4566 billion yuan, an increase of $15.9 \%$. The number of inbound tourists was 139 million, and increased by $0.8 \%$. Among the inbound tourists, there were 60 million 740 thousand overnight visitors, an increase of $2.5 \%$. International tourism revenue was 123 billion 400 million dollars, up $2.9 \%$. The number of outbound domestic residents reached 142 million 730 thousand, an increase of $5.6 \%$. The main economic indicators of tourism showed a good trend, and the growth of tourism consumption and comprehensive benefits was strong, which laid a solid foundation for the leap forward development of cultural tourism. In general, the situation of the development of the national tourism industry has been continuously improved, the status of tourism in the national economic development has been steadily improved, and the rich cultural tourism resources have been gradually excavated, and the potential for development is gradually released.

\section{THE PROBLEM OF THE DEVELOPMENT OF THE CUlTURAL TOURISM INDUSTRY IN CHINA}

For many years, the development level of Chinese cultural tourism industry has been steadily improved, but it still faces some deep-seated problems which deserve attention, which is mainly manifested in the lack of the close 
integration of the cultural and the tourism, and the connotation of industrial development needs to be rammed. In the background of the rapid development of China's tourism industry, the magical and unique features of China's tourism lie in its beautiful landscape and its unique historical culture. It lies in the stories in the mountains and rivers, the history behind the mountains and rivers, the integration of the mountains the seas and the historical culture, and the cultural connotation of the tourist attractions. However, most of the tourism industry in China still relies on natural landscapes; overemphasize the landscape of natural resources, mainly tourism and tourism, Lack of attention to the humanistic landscape. Tourism development is excessively dependent on "ticket economy", the cultural connotation of tourism resources is not fully excavated, the potential is not fully aroused, cultural tourism industry has not yet formed its scale and its development quality is not high, which has seriously hindered the development of China's tourism industry. Therefore, it is necessary to inject the soul of culture into the tourism industry, to stimulate and promote tourism with culture to develop tourism industry, to accelerate the integration of culture and tourism, to stimulate the explosive force of the development of China's tourism industry and to promote the growth and development of the national tourism industry in an all-round way.

\section{The Main Measures to MaKe China's CulturaL TOURISM BETTER}

At present, China is fully promoting the development strategy of "The Belt and Road Initiative", and has been actively responding by many countries in the world, and has made positive progress. We should firmly grasp this rare historical opportunity to introduce the Chinese cultural tourism industry to the world, and believe that the Chinese cultural and Tourism industry will take this opportunity to sail to more and reach High goal. We should actively build the brand of "the year of Silk Road Tourism" established by the National Tourism Administration, and promote the continuous force of "The Belt and Road Initiative" effect. In this context, China's tourism development is worth looking forward to. The development of China's cultural and tourism industry will make it an important pillar industry in China on the basis of overcoming difficulties.

First of all, we should strive to achieve the same emphasis on the construction of scenic spots and supporting facilities, and promote the transformation of tourism development from monomer development to cluster development. Taking the comprehensive deepening of comprehensive tourism reform as an opportunity, we can further accelerate the improvement of tourism management system. Taking the market as the guidance, we must encourage the scenic spots to take the form of resources, management rights and other forms to introduce external funds, and adopt the means of market operation, dig into the development potential of the cultural scenic spots, and to stimulate the vitality of the development of cultural scenic spots. At the same time, we should accelerate the cultivation of characteristic cultural tourism brands, further enrich the types of cultural tourism commodities, speed up the construction of leisure and entertainment mall, characteristic catering street and special commodity shopping city, Create cultural connotations of scenic spots and improve the valueadded of tourism industry.

Secondly, efforts should be made to promote the innovation of tourism publicity and promotion. Promote the transformation of tourism information from a single channel to a three-dimensional channel. The network propaganda, especially the intelligent tourism construction as the key point, is devoted to planning and promulgation of the intelligent tourism support and incentive policy, supporting the tourism industry units to carry out the intelligent tourism construction, promoting the intelligent development of tourist attractions, optimizing publishing system of the public information platform, and strengthening the cooperation with the well-known network media. Organize and plan to carry out a series of influential activities through attention and influence of the city tourism administration network, microblog, WeChat, APP platform.

Finally, it is necessary to further improve and optimize the level of the tourism environment service and promote the transformation from satisfying the basic tourism needs to providing high-quality tourism services. In order to improve the tourism brand's gold content as an important direction of tourism development, we should further improve the service system of "eating and living, tour, shopping, entertainment and health". At the same time, we should improve and implement the exit mechanism of tourism brand, and strengthen the Supervision and review of tourist brands, such as tourist grade of the scenic spots, rural tourist attractions, star wine shops and travel agencies, and so on. At the same time, it is necessary to further improve the training of tourism professionals, establish and improve the talents Library of excellent tour guide, the library of tourism training teachers, the judges Library of tourism competition, and organize special training and Study on hotel management, tour guide explanation and rural tourism so as to improve the soft strength of tourism development.

\section{SUGGESTIONS ON THE INTEGRATION OF CHINESE CULTURE AND TOURISM}

In order to improve the brand image of China's tourism with the "whole country chess" pattern, the national cultural landscape resources should be summarized, the individual characteristics of cultural tourism should be grasped accurately, the transformation and upgrading of the regional tourism industry should be promoted by cultural creativity and advanced technology, and the explosive force of the development of Chinese cultural tourism should be fully stimulated. Static resources should be integrated on the level of cultural values, cultural value should be orientated by historical resources, cultural and aesthetic interest in historical relics into cultural products with the ideal and desire color of contemporary people, so that they can interact with the spirit of contemporary people and realize the product of cultural resources.

First, strengthen the development plan of cultural tourism industry. We should focus on the realization of the 
development orientation of the transformation from the tourism resources country to the great tourism country, Perfected the planning of the cultural tourism industry at a high level and the high starting point, speed up the optimization of the scientific layout of the national cultural tourism, the integration of cultural tourism resources, the strengthening of regional cooperation, the unified design of the cultural and cultural tourism lines, the cultural tourism projects, and the unified design of the cultural and cultural tourism marketing strategy. making the national cultural tourism consistent and consistent, and making the international brand image of "China Tourism", setting up a new pattern of "the whole country" tourism development, which is "the resources sharing, the information exchange, the complementary advantages, the dislocation development, the win-win cooperation and win-win", and the promotion of the cultural tourism agglomeration.

The two is to cultivate new forms of cultural tourism with cultural creativity. Cultural creativity can activate the intangible resources of the region, turn invisible resources into fashionable consumer goods, and make limited tourism resources unlimited. China should improve the cultural connotation of tourism products from the perspective of creativity, cultivate new cultural tourism format, realize the tourism industry from low to high end, from quantity to quality, from domestic to international, from excessive reliance on resources and investment to rely on industrial innovation and talent resources change.

The three is to promote intelligent tourism with information technology. With the experience gained by the developed countries in tourism intelligence, China should digitize the tourism industry in the background of the new information technology, such as cloud computing, the Internet of things, high speed Internet and other new information technologies. China should carry out the digital management and management of tourism, promote the construction of tourism website, tourist call system, tourism database and other information platforms with the help of modern information technology, effectively integrate the tourism resources, carry out scientific and unified management of scenic spots, locate tourists and find them with the help of these platforms. In response to the needs of tourists, we will constantly improve service functions, provide tourists with more, better and more convenient travel services, improve the satisfaction of tourists, explore and build virtual tourism centers, take the lead in experiencing regional tourism landscape, stimulate the interest of tourists and expand the demand of the tourism market.

The four is to seize the new highland of leisure tourism with the advantages of cultural resources. Grasp the trend of tourism industry development from sightseeing tour to leisure vacation tour, make great efforts to break through the traditional development road of ticket economic mode, rely on regional ecology, mountain and sea and ancient cultural resources, vigorously develop leisure travel, holiday tour, experience tour and other cultural projects, and extend tourism consumption through time and space, that is, development The night life industry of tourist attractions extends tourism consumption in time. In tourist attractions, building bars, book bars, tourist information exchange sites, theaters, and so on, extend tourism consumption in space, and promote the transformation and development of traditional sightseeing tourism to entertainment and leisure.

The five is to Shaping cultural tourism products and actively expanding the international market. The development of cultural industry is an important way to meet the diversified spiritual and cultural needs of the people under the socialist market economy. We must adhere to the direction of advanced socialist culture, adhere to the unity of social benefits in the first place, adhere to the unity of social and economic benefits, and promote the leapfrog development of cultural industry in accordance with the requirements of comprehensive and sustainable development, and make it a new economic growth point, make it an important point of strategic adjustment of the economic structure and the transformation of the economic structure. The important point of economic development mode is to provide important support for promoting scientific development. To the inside, Chinese cultural tourism should pay more attention to the improvement of the quality of its own cultural development. On the basis of absorbing the achievements of other regions' cultural tourism development, we should continuously excavate the characteristics of its own cultural tourism, pay attention to the molding and publicity of its own cultural tourism image, and promote the comprehensive sustainable development of Chinese cultural tourism. To the outside world, we should cultivate cultural confidence, adhere to the development of a multi-level and wide field of foreign cultural exchange, carry out the strategy of going out of culture, constantly enhance the international influence of Chinese culture, and show the new image of China's reform and opening to the world and the spirit of the Chinese nation.

\section{CONCLUSION}

In a word, under the background of complex changes in the current international economic and political environment, China should attach more importance to cultural influence and integrate culture and tourism closely. the development of Chinese cultural tourism industry should be fully planned, conform to the situation of China's economic transformation and development, adapt to the needs of social consumption upgrading, fully display the charm of Chinese culture, and combine culture with tourism, and form a powerful motive for industrial development. More importantly, we should firmly grasp the opportunity of "The Belt and Road Initiative", actively introduce tourism resources to countries along the line, fully integrate into the large pattern of international tourism development, and realize the sustainable and prosperous development of the tourism industry.

\section{REFERENCES}

[1] Liang yong, Gong jianwen.Promoting the rise of tourism industry in our province by cultural tourism [N], JiangXi daily.2013-11-04

[2] Xu li, Gao subiao.To undertake the spillover effect, the tourism of the city needs to be strengthened[N], Lianyungang daily.2015-1-29 
[3] He xiongwei, Chen jin.Analysis of the integration and development of cultural industry and tourism industry-Based on Jiangxi's Empirical Research[J], Business economic magazine.2013(12).

[4] Gao subiao, Ji wenhua.Sound promotion in the truth and innovation[N], JiangSu economic newspaper.2014-12-29

[5] National Bureau of Statistics.People's Republic of China 2017 national economic and social development statistical bulletin[J].China Statistics magazine.2018(3).

[6] Akinboade OA, Braimoh LA.International tourism and economic development in South Africaa Granger causality test [J].International Journal of Tourism Research, 2010,12(2):149-163.

[7] Tang CF, Tan EC. Does tourism effectively stimulate Malaysia's economic growth?[J].Tourism Management, 2015, 46:158-163.

[8] Kim HJ, Chen MH, Jang SS. Tourism expansion and economic development: The case of Taiwan[J].Tourism Management, 2006, 27(5):925-933.

[9] Oh C-O.The contribution of tourism development to economic growth in the Korean economy[J].Tourism Management, 2005, 26(1):39-44.

[10] Cortés-Jiménez I .Which type of tourism matters to the regional economic growth? The cases of Spain and Italy [J].International Journal of Tourism Research, 2008,10(2):127-139.

[11] Seetanah B.Assessing the dynamic economic impact of tourism for island economies[J].Annals of Tourism Research, 2011, 38(1):291308.

[12] Muchapondwa E, Stage J.The economic impacts of tourism in Botswana, Namibia and South Africa Is poverty subsiding? [J].Natural Resources Forum, 2013, 37(2):80-89.

[13] Cárdenas-García PJ, Sánchez-Rivero M.Tourism and economic development: analysis of geographic features and infrastructure provision [J].Current Issues in Tourism, 2013.

[14] Andergassen R, Candela G.Less Developed Countries, Tourism Investments and Local Economic Development[J].Review of Development Economics, 2013,17(1):16-33.

[15] Belloumi M.The relationship between tourism receipts, real effective exchange rate and economic growth in Tunisia [J].International Journal of Tourism Research, 2010,12(5):550-560.

[16] Balaguer J, Cantavella-Jordá M.Tourism as a long-run economic growth factor: The Spanish case [J].Applied Economics, 2002, 34(7):877-884.

[17] Chou MC.Does tourism development promote economic growth in transition countries? Apanel data analysis [J].Economic Modelling, 2013, 33:226-232.

[18] Dritsakis N.Tourism as a long-run economic growth factor: An empirical investigation for Greece using causality analysis [J].Tourism Economics, 2004, 10(3):305-316.

[19] Hughes HL.Tourism multiplier studies: a more judicious approach[J].Tourism Management,1994, 15(6):403-406.

[20] Boukas N, Ziakas V.Impacts of the Global Economic Crisis on Cyprus Tourism and Policy Responses [J].International Journal of Tourism Research, 2013,15(4):329-345.

[21] Roy Ballantyne, Jan Packer, John Falk.Visitors, learning for environmental sustainability:Testing short - and long -term impacts of wildlife tourism experiences using structural equation modeling $[\mathrm{J}]$. Tourism Management, 2011, 32 (6):1243 -1252. 